\title{
Corrigendum: Chromosome-Level Genome Assembly Reveals Signifificant Gene Expansion in the Toll and IMD Signaling Pathways of Dendrolimus kikuchii
}

\author{
Jielong Zhou ${ }^{1}$, Peifu $\mathrm{Wu}^{2}$, Zhongping Xiong ${ }^{1}$, Naiyong Liu ${ }^{1}$, Ning Zhao ${ }^{2}, \mathrm{Mei}_{\mathrm{Ji}}{ }^{3}$, Yu Qiu ${ }^{2}$ and \\ Bin Yang ${ }^{1 *}$ \\ ${ }^{1}$ Key Laboratory of Forest Disaster Warning and Control of Yunnan Province, Southwest Forestry University, Kunming, China \\ ${ }^{2}$ College of Life Science, Southwest Forestry University, Kunming, China, ${ }^{3}$ Yunnan Academy of Forestry and Grassland, Kunming, \\ China
}

Keywords: lepidoptera, Dendrolimus kikuchii, nanopore, $\mathrm{Hi}-\mathrm{C}$, chromosome-level genome, gene expansion, toll and Imd pathways

\section{A Corrigendum on}

\section{OPEN ACCESS}

Edited and reviewed by: Ben-Yang Liao,

National Health Research Institutes,

Taiwan

${ }^{*}$ Correspondence: Bin Yang

yangbin48053@swfu.edu.cn

Specialty section:

This article was submitted to Evolutionary and Population Genetics,

a section of the journal

Frontiers in Genetics

Received: 02 November 2021 Accepted: 08 November 2021

Published: 24 November 2021

Citation:

Zhou J, Wu P, Xiong Z, Liu N, Zhao N, Ji M, Qiu Y and Yang B (2021)

Corrigendum: Chromosome-Level

Genome Assembly Reveals

Signifificant Gene Expansion in the Toll and IMD Signaling Pathways of

Dendrolimus kikuchii.

Front. Genet. 12:807396.

doi: 10.3389/fgene.2021.807396
Chromosome-Level Genome Assembly Reveals Signifificant Gene Expansion in the Toll and IMD Signaling Pathways of Dendrolimus kikuchii by Zhou, J., Wu, P., Xiong, Z., Liu, N., Zhao, N, Ji, M, Qiu, Y and Yang, B. (2021) Chromosome-Level Genome Assembly Reveals Significant Gene Expansion in the Toll and IMD Signaling Pathways of Dendrolimus kikuchii. Front. Genet. 12:728418. doi: 10.3389/fgene.2021.728418

In the original article, Figure 7 and Figure 8 were published incorrectly. These figures were swapped in error. The corrected Figure 7 and Figure 8 appear below:

In addition, there were errors in the original article as published. Figure 7 was erroneously cited in place of Figure 8 in two sentences in the section Results and Discussion, Expression of Genes in the Toll and IMD signaling pathways, Paragraph 2. The following corrections have been made in this paragraph:

'such as LG29_G00170/171/173 belonged to cluster 1 and were highly expressed only at 3 instar larvae (Figure 8, Supplementary Table S11).'

'Just three out of the 19 genes showed significantly higher expression in only one sample than the remaining 11 samples (Figure 8, Supplementary Table S11).'

The authors apologize for this error and state that this does not change the scientific conclusions of the article in any way. The original article has been updated.

Publisher's Note: All claims expressed in this article are solely those of the authors and do not necessarily represent those of their affiliated organizations, or those of the publisher, the editors and the reviewers. Any product that may be evaluated in this article, or claim that may be made by its manufacturer, is not guaranteed or endorsed by the publisher.

Copyright $\odot 2021$ Zhou, Wu, Xiong, Liu, Zhao, Ji, Qiu and Yang. This is an open-access article distributed under the terms of the Creative Commons Attribution License (CC BY). The use, distribution or reproduction in other forums is permitted, provided the original author(s) and the copyright owner(s) are credited and that the original publication in this journal is cited, in accordance with accepted academic practice. No use, distribution or reproduction is permitted which does not comply with these terms. 


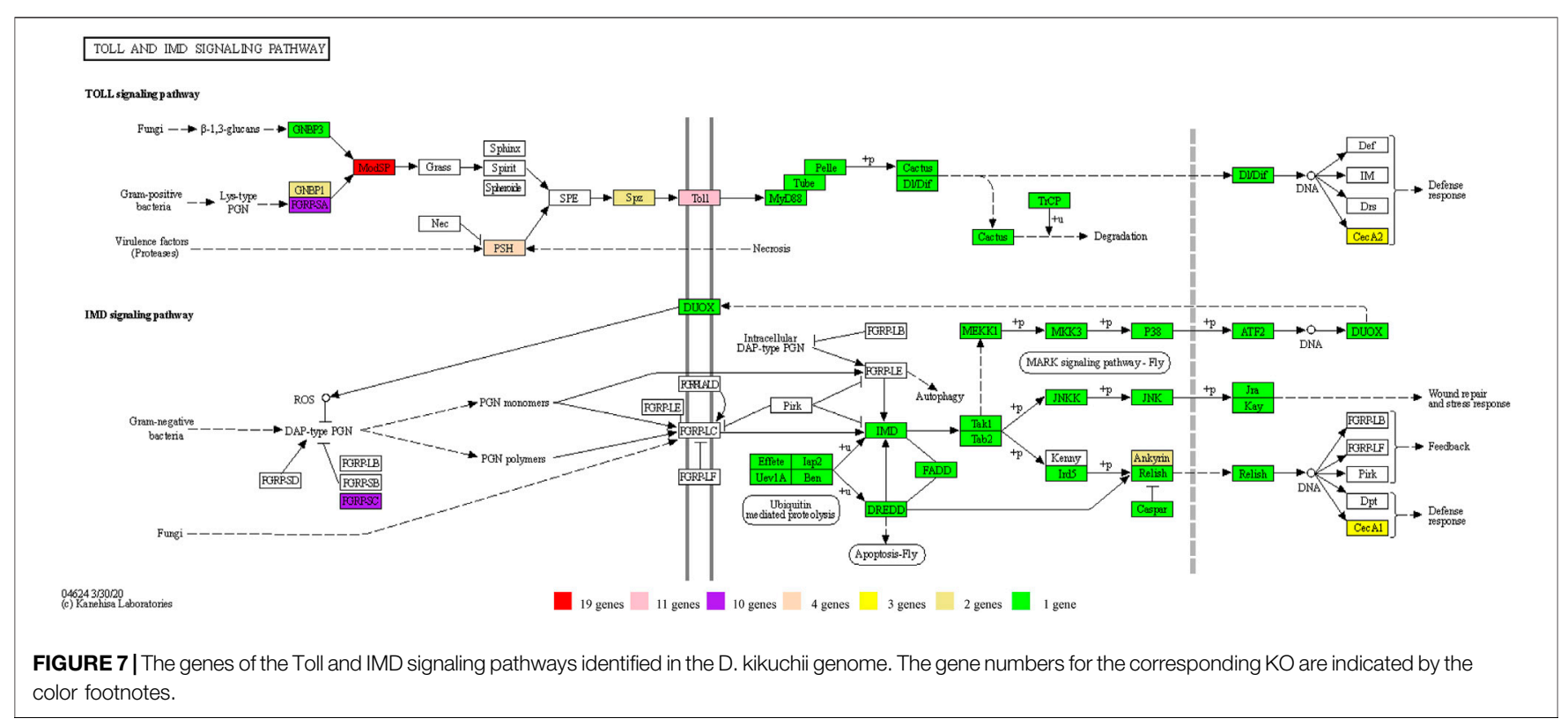




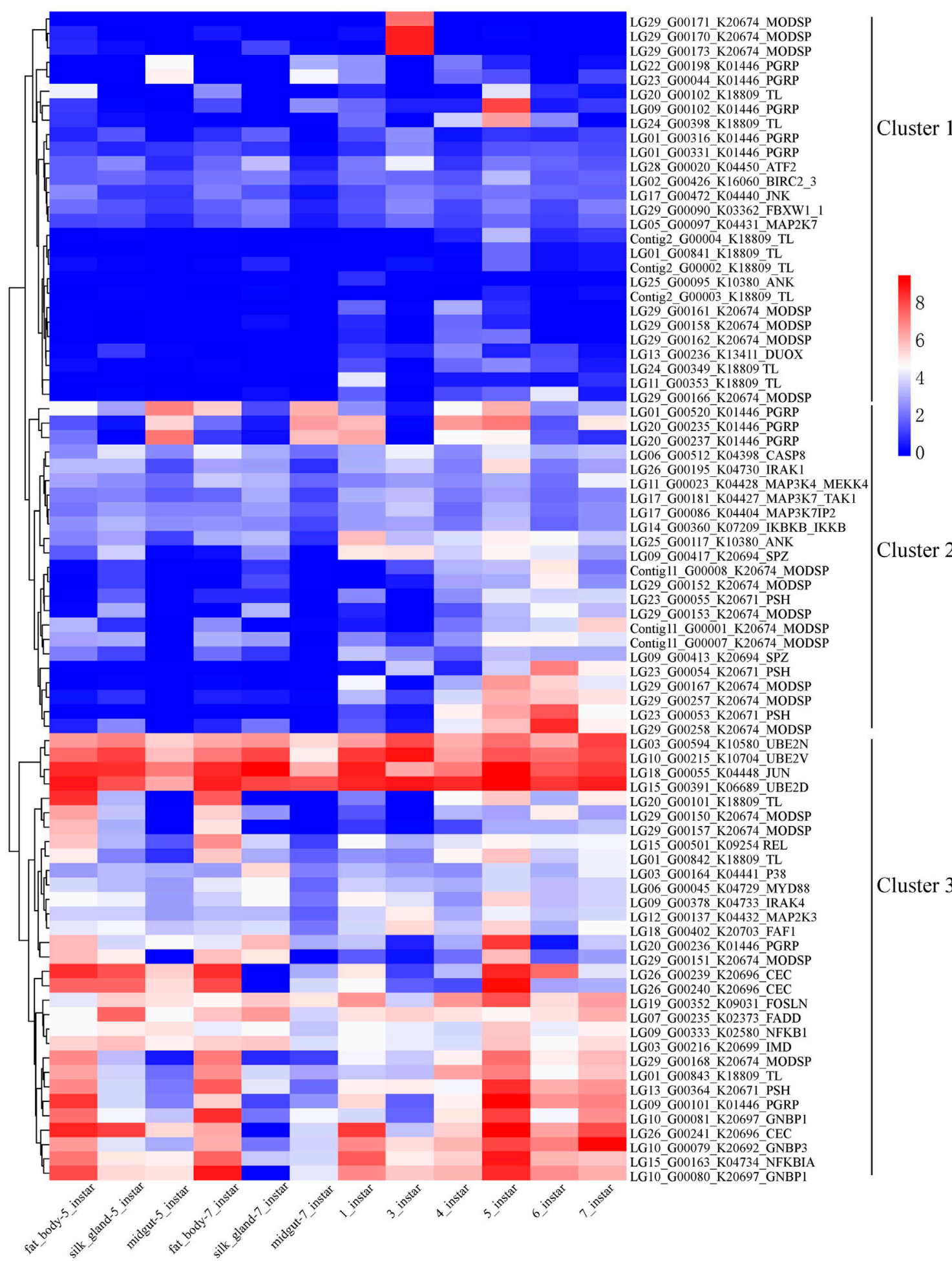

FIGURE 8 | Clustering gene expression pattern of the significantly expanded genes of the Toll and IMD signaling pathways. Note: Each column represents one sample, each row represents one gene. All the FPKM values of genes in the pathway were transformed with log2, and then normalized into Z-scores along the rows. The log2 values were color-coded as shown in the color bar. 